\title{
A near miss case of placenta percreta in a patient with post myomectomy scar
}

\author{
Vinita Singh*, Rajshree Sahu, Esha Das, Pavan B. C.
}

Department of Obstetrics and Gynecology, AIIMS, Raipur, Tatibandh, G. E. Road, Raipur, Chhattisgarh, India

Received: 03 October 2019

Accepted: 07 November 2019

\section{*Correspondence:}

Dr. Vinita Singh,

E-mail: ddvinitasingh@gmail.com

Copyright: $\odot$ the author(s), publisher and licensee Medip Academy. This is an open-access article distributed under the terms of the Creative Commons Attribution Non-Commercial License, which permits unrestricted non-commercial use, distribution, and reproduction in any medium, provided the original work is properly cited.

\begin{abstract}
The term placenta accreta or placenta accrete syndrome is used to describe a spectrum of an abnormal placental implantation and firm adherence which are classified according to the depth of invasion into the uterus. A 28-year-old elderly primigravida presented AIIMS OPD to for the $1^{\text {st }}$ time at $13+2$ weeks of gestation with brownish discharge per vaginum. Ultrasonography done showed 12 weeks single intrauterine pregnancy with subchorionic haemorrhage of $3.7 \times 2.52 \mathrm{~cm}$ with placenta being fundoanterior. She underwent myomectomy 2 years back and during her antenatal care in 3rd trimester growth scan at 30+2 weeks of gestation placenta was fundoanterior with loss of retroplacental hypoechoic in the upper margin of placenta at the myomectomy scar site with small extra uterine collection seen measuring $7.6 \times 2.3 \mathrm{~cm}$ and hence possibility of placenta accreta was suggestive by the above findings confirmed by MRI. Emergency cesarean section done at 36+6 weeks of gestation for leaking per vaginum. Manual removal of placenta was tried but it failed and soon atonic PPH developed. Seeing no response with uterotonics internal iliac artery ligation was also attempted but failed. Immediate decision for hysterectomy was taken as a life-saving method. On adhesiolysis in the fundal region placental tissue perforating uterine serosa was visible on the surface of uterus, hence diagnosis of placenta percreta was confirmed which was further confirmed on histopathological report. Currently hysterectomy or local resection is preferred over conservative management with methotrexate.
\end{abstract}

Keywords: Critical care obstetrics, Obstetrics diagnosis and management, Placental pathology, Post-partum hemorrhage

\section{INTRODUCTION}

The term placenta accreta or placenta accrete syndrome is used to describe a spectrum of an abnormal placental implantation and firm adherence which are classified according to the depth of invasion into the uterus. These include placenta accreta when chorionic villi are adhered to the myometrium with no intermediate decidual layers, increta when the villi invades into the myometrium and percreta when villi completely penetrates the myometrium reaching serosa with or without breaching serosa and invading the surrounding structures, such as the bladder, broad ligament, or sigmoid colon., ${ }^{1,2}$ These are further described on the basis of the number of lobules involved as total placenta accrete involving all lobules, partial placenta accrete involving at least two but not all lobules and focal placenta accreta involving only a single lobule. ${ }^{2}$ Definitive diagnosis of placenta accreta is made on visualization of chorionic villi embedded in myometrium with absence of the decidual layer between them in histopathological examination.

Antenatal diagnosis is based on identifying risk factors and use of imaging techniques (ultrasonography and 
MRI). The use of colour flow doppler imaging may facilitate the diagnosis. Doppler findings of placenta accrete spectrum include Turbulent lacunar blood flow, increased sub placental vascularity, gaps in myometrial blood flow, and vessels bridging the placenta to the uterine margin. ${ }^{3}$ MRI is typically not indicated after a negative screening ultrasound due to relatively high negative predictive value of USG.

\section{CASE REPORT}

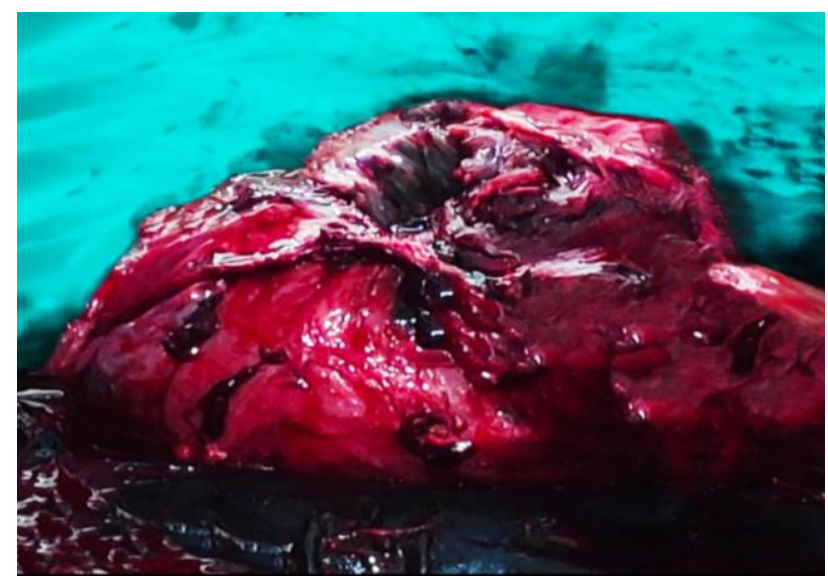

Figure 1: Placenta percreta perforating uterine serosa at fundus of uterus in the region of previous myomectomy scar.

A 28-year-old elderly primigravida presented to AIIMS OPD for the 1 st time at $13+2$ weeks of gestation with brownish discharge per vaginum. All her routine antenatal blood and urine investigations were found to be normal. Ultrasonography done showed 12 weeks single intrauterine pregnancy with sub-chorionic haemorrhage of $3.7 \times 2.52 \mathrm{~cm}$ with placenta being fundoanterior. She gave no significant other history except she underwent myomectomy 2 years back for large fundal uterine myoma of $10 \times 8 \mathrm{~cm}$. She got her TIFA(Targetted imaging of fetal anomalies) scan done which should showed single intrauterine fetus of $18+5$ weeks with no gross congenital anomalies in fetus. Multiple fibroids were found in the uterus of size ranging from 3 to $5 \mathrm{~cm}$ on the anterior wall of uterus. Uterine artery Doppler showed high impedance blood flow. Her $3^{\text {rd }}$ trimester growth scan done at $30+2$ weeks of gestation showed single live intrauterine fetus of $29+2$ weeks with placenta being fundoanterior with loss of retroplacental hypoechoic in the upper margin of placenta at the myomectomy scar site with small extra uterine collection seen measuring $7.6 \times 2.3 \mathrm{~cm}$ and hence possibility of placenta accreta was suggestive by the above findings. Also, multiple fibroid of size ranging from 3 to $5 \mathrm{~cm}$ was visible on anterior, lateral and subserosal region of uterus. Both sided uterine artery doppler showed high impedence and pulsatility index was 1.9 (> 99 percentile). Early diastolic notch was persistent on left side. MRI was advised which further confirmed the possibility of placenta percreta. Elective cesarean section was planned at 37 completed weeks.
Patient got admitted in emergency hours at $36+6$ weeks of gestation with complain of leaking per vaginum. Manual removal of placenta was tried but it failed and soon atonic PPH developed. Seeing no response with uterotonics internal iliac artery ligation was also attempted but failed. Immediate decision for hysterectomy was taken as a life-saving method and after proper counselling and consent. Dense adhesions were present in the fundal region which on adhesiolysis showed placental tissue invading uterine myometrium and visible on the surface of uterus (Figure 1), hence diagnosis of placenta percreta was confirmed. Subtotal hysterectomy done. Later histopathological report too confirmed the diagnosis of placenta percreta.

\section{DISCUSSION}

Placenta accreta causes considerable maternal morbidity and mortality and is the major indication for emergency peri-partum hysterectomy. ${ }^{4}$

Four different primary methods of conservative management have been described in the international literature to avoid peripartum hysterectomy. ${ }^{5}$

1. The extirpative technique (manual removal of the placenta)

2. Leaving the placenta in situ or the expectant approach

3. One-step conservative surgery (removal of the accrete area); and

4. The triple- P procedure (suturing around the accrete area after resection). These methods have been used alone or in combination and in many cases with additional procedures such as those proposed by interventional radiology.

Once should not attempt forcible removal of an invasive placenta where the placental villi have invaded the deep uterine vasculature as it would increase the risks of massive obstetric haemorrhage and would lead to salvation hysterectomy. ${ }^{6}$

Additional procedures (i.e. embolization or vessel ligation, temporal internal iliac balloon occlusion, methotrexate, hysteroscopic resection of retained tissues) have been used in a conservative approach with the placenta left in situ to decrease morbidity or to accelerate placental resorption. ${ }^{7}$ Embolization before performing hysterectomy may reduce the risk of intraoperative blood loss and prophylactic devascularization may prevent the occurrence of secondary haemorrhage and could also accelerate placental resorption. ${ }^{8-10}$ Overall, these uterinesparing procedures seem to be less effective in cases of placenta accreta spectrum (PSA) disorders. ${ }^{11,12}$

ACOG and FIGO consensus guidelines on placenta accreta spectrum disorders supports hysterectomy or local resection over conservative management. Overall, the use of methotrexate is not recommended until further 
evidence is available on its efficacy and safety. ${ }^{13}$ Neutropenia or medullar aplasia and other possible complications, such as secondary infection of a placenta left in situ. ${ }^{14}$

\section{CONCLUSION}

Preparation for delivery and postpartum care of placenta accreta patients should involve a multidisciplinary team and early ante partum consultations guided by the levels of maternal care. Taking these limited published data together, and the accepted approach of hysterectomy to treat placenta accreta spectrum, conservative management or expectant management should be considered only for carefully selected cases of placenta accreta spectrum after detailed counselling about the risks, uncertain benefits, and efficacy and should be considered investigational.

\section{ACKNOWLEDGMENTS}

Patient is sincerely acknowledged for its cooperation and contribution during preparation of this manuscript.

Funding: No funding sources

Conflict of interest: None declared

Ethical approval: Not required

\section{REFERENCES}

1. Cunningham FG, Williams JW. Obstetrical hemorrhage. In: Cunningham FG, Leveno KJ, Bloom SL, et al, editors. William's obstetrics. $23^{\text {th }}$ edition. New York: McGraw-Hill, Medical; 2010:776-780.

2. Wortman AC, Alexander JM. Placenta accreta, increta, and percreta. Obstet Gynecol Clin North Am. 2013;40(1):137-54.

3. Bowman ZS, Eller AG, Bardsley TR, Greene T, Varner MW, Silver RM. Risk factors for placenta accreta: a large prospective cohort. Am J Perinatol. 2014;31:799-804.

4. Tikkanen M, Paavonen J, Loukovaara M, Stefanovic V. Antenatal diagnosis of placenta accreta leads to reduced blood loss. Acta Obstet et Gynecol Scandinavica. 2011;90(10):1140-6.

5. Sentilhes L, Kayem G, Chandraharan E, PalaciosJaraquemada J, Jauniaux E. For the FIGO placenta accreta diagnosis and management expert consensus pane: FIGO consensus guidelines on placenta accreta spectrum disorders: Conservative management. Int J Gynecol Obstet. 2018;140:291-8.
6. Jauniaux E, Collins SL, Burton GJ. The placenta accreta spectrum: Pathophysiology and evidencebased anatomy for prenatal ultrasound imaging. Am J Obstet Gynecol . 2017; pii:S0002-9378(17)30731-7.

7. Sentilhes L, Goffinet F, Kayem G. Management of placenta accreta. Acta Obstet Gynecol Scand. 2013;92:1125-34.

8. Angstmann T, Gard G, Harrington T, Ward E, Thomson A, Giles W. Surgical management of placenta accreta: cohort series and suggested approach. Am J Obstet Gynecol. 2010;202:38.e138.e9.

9. Bouvier A, Sentilhes L, Thouveny F, Bouet PE, Gillard P, Willoteaux S, et al. Planned caesarean in the interventional radiology cath lab to enable immediate uterine artery embolization for the conservative treatment of placenta accreta. Clin Radiol. 2012;67:1089-94.

10. Soyer P, Sirol M, Fargeaudou Y, Bour L, Morel O, Dohan A, et al. Placental vascularity and resorption delay after conservative management of invasive placenta: MR imaging evaluation. Eur Radiol. 2013;23:262-71.

11. Sentilhes L, Trichot C, Resch B, Sergent F, Roman H, Marpeau L, Verspyck E. Fertility and pregnancy outcomes following uterine devascularization for severe postpartum haemorrhage. Hum Reprod. 2008;23(5):1087-92.

12. Sentilhes L, Gromez A, Clavier E, Resch B, Verspyck E, Marpeau L. Predictors of failed pelvic arterial embolization for severe postpartum hemorrhage. Obstet Gynecol. 2009;113:992-9.

13. Sentilhes L, Kayem G, Chandraharan E, PalaciosJaraquemada J, Jauniaux E. FIGO placenta accreta diagnosis and management expert consensus panel, Duncombe G, Klaritsch P, Chantraine F, Kingdom J, Grønbeck L. FIGO consensus guidelines on placenta accreta spectrum disorders: conservative management. Int J Gynecol Obstet. 2018;140(3):2918.

14. Sentilhes L, Ambroselli C, Kayem G, Provansal M, Fernandez H, Perrotin F, et al. Maternal outcome after conservative treatment of placenta accreta. Obstet Gynecol. 2010;115(3):526-34.

Cite this article as: Singh V, Sahu R, Das E, Pavan BC. A near miss case of placenta percreta in a patient with post myomectomy scar. Int J Reprod Contracept Obstet Gynecol 2019;8:5062-4. 